Virginia Commonwealth University VCU Scholars Compass

2002

\title{
Caging of Ni clusters by benzene molecules and its effect on the magnetism of $\mathrm{Ni}$ clusters
}

B. K. Rao

Virginia Commonwealth University

P. Jena

Virginia Commonwealth University

Follow this and additional works at: http://scholarscompass.vcu.edu/phys_pubs

Part of the Physics Commons

Rao, B. K., Jena, P. Caging of Ni clusters by benzene molecules and its effect on the magnetism of Ni clusters. The Journal of Chemical Physics 116, 1343 (2002). Copyright ( 2002 AIP Publishing LLC.

\section{Downloaded from}

http://scholarscompass.vcu.edu/phys_pubs/162

This Article is brought to you for free and open access by the Dept. of Physics at VCU Scholars Compass. It has been accepted for inclusion in Physics Publications by an authorized administrator of VCU Scholars Compass. For more information, please contact libcompass@vcu.edu. 


\title{
Caging of Ni clusters by benzene molecules and its effect on the magnetism of Ni clusters
}

\author{
B. K. Rao and P. Jena \\ Physics Department, Virginia Commonwealth University, Richmond, Virginia 23284-2000
}

(Received 26 July 2001; accepted 30 October 2001)

\begin{abstract}
Global optimization of the geometry of small Ni clusters interacting with benzene molecules yields equilibrium structures where the $\mathrm{Ni}$ atoms find themselves caged between the benzene molecules. This leads to quenching of the $\mathrm{Ni}$ magnetic moment in most of the complexes even though the structure of the caged Ni clusters remain relatively unchanged from their otherwise free gas phase geometry. The accuracy of these predictions, based on density functional theory with generalized gradient approximation for exchange and correlation, is established by the good agreement achieved between the calculated and available experimental dissociation energies and ionization potentials. (C) 2002 American Institute of Physics. [DOI: 10.1063/1.1429245]
\end{abstract}

\section{INTRODUCTION}

The passivation of metal clusters by organic ligands is one of the ways to prevent them from coalescing during cluster assembly. Since the interaction of the ligand atoms with the metal atoms is likely to change the properties of otherwise bare metal clusters, a fundamental understanding of this interaction is necessary for tailor-making cluster-assembled materials. With this in mind, a considerable amount of experimental work has been recently carried out on metalloorganic complexes ${ }^{1}$ as well as metal oxide clusters coated with organic ligands. ${ }^{2}$ For example, a series of experiments $^{3-21}$ involving organic molecules such as benzene interacting with $3 d$ transition metal atoms $(\mathrm{Sc}, \mathrm{Ti}, \mathrm{V}, \mathrm{Cr}, \mathrm{Mn}$, $\mathrm{Fe}, \mathrm{Co}$, and $\mathrm{Ni}$ ) in the gas phase have been carried out, thus eliminating the complicating factor associated with the role of solvents.

In particular, we focus on the work of Kaya and co-workers. ${ }^{22}$ These authors have measured the mass spectra, ionization potentials, reactivity, and in some restricted cases, electron affinities of transition metal-benzene complexes systematically. They observed that while the dominant peaks in the mass ion spectra of metal-benzene complexes involving the early part of the $3 d$-series $\left(\mathrm{M}_{n} \mathrm{Bz}_{m} ; \mathrm{M}=\mathrm{Sc}, \mathrm{Ti}, \mathrm{V}\right.$, $\mathrm{Cr}, \mathrm{Mn}$ ) are characterized by one excess benzene molecule for every metal atom, $(m=n+1)$, the number of metal atoms in $\mathrm{Co}_{n}(\mathrm{Bz})_{m}$ and $\mathrm{Ni}_{n}(\mathrm{Bz})_{m}$ can even exceed those of benzene molecules $(n>m)$. More importantly, in $\mathrm{Ni}_{n}(\mathrm{Bz})_{m}$ complexes containing the maximum, $m_{\max }$ number of benzene molecules for each metal composition, $n$ are unreactive towards $\mathrm{NH}_{3}$ while $\mathrm{M}_{n}(\mathrm{Bz})_{m}(\mathrm{M}=\mathrm{Sc} \cdots \mathrm{Cr})$ complexes with $n \geqslant m$ are reactive. These results seem to indicate that the geometry and electronic structure of $\mathrm{Ni}_{n}(\mathrm{Bz})_{m}$ complexes are fundamentally different from those involving early $3 d$-metal atoms. No theoretical explanation of this unusual behaivor of Ni-benzene complexes is available in the literature.

Several theoretical calculations ${ }^{23-28}$ have been carried out to understand the geometry, relative stability, and dissociation energy of these complexes. One of the early sys- tematic studies in this regard is due to that of Bauschlicher and co-workers ${ }^{25}$ who studied $3 d$ metal atoms adsorbed on benzene using a $C_{6 v}$ symmetry. The present authors and their collaborators ${ }^{26,27}$ have studied $3 d$ metal atoms atop a benzene molecule using $C_{6 v}$ symmetry and those sandwiched between two benzene molecules using $D_{6 h}$ symmetry. Bowers and co-workers ${ }^{20}$ have studied larger complexes involving $\mathrm{V}$ and benzene. No calculations of the structure of $\mathrm{Ni}_{n}(\mathrm{Bz})_{m}(n, m>1)$ exist where geometries were optimized without any symmetry constraint. In this paper we present the first fully optimized geometries of $\mathrm{Ni}_{n}(\mathrm{Bz})_{m}$ and $\mathrm{Ni}_{n}(\mathrm{Bz})_{m}^{+}(n \leqslant 3, m \leqslant 2)$ complexes with no symmetry constraint. The dissociation energies, ionization potentials, and magnetic moments are calculated using density functional theory with generalized gradient approximation (DFT-GGA) for exchange and correlation. The accuracy of these predicted results is established by comparing them with available experiment. In Sec. II we briefly describe the computational procedure. The results are discussed in Sec. III. A summary of our conclusions is given in Sec. IV.

\section{COMPUTATIONAL PROCEDURE}

The calculations were carried out using the linear combination of atomic orbitals-molecular orbital (LCAO-MO) approach. The atomic wave functions were represented by Gaussian orbitals (LANL2DZ basis). ${ }^{29}$ To assess the accuracy of these basis functions, we have repeated the calculations of the $\mathrm{NiBz}$ cluster using an all-electron triple zeta basis set with extra polarization functions $\left(6-311 \mathrm{G}^{* *}\right) .{ }^{29}$ The total energies were calculated using the density functional theory (DFT) and generalized gradient approximation (GGA) for exchange-correlation contribution. The BeckePerdew-Wang (commonly referred to as BPW91) form of the functional and the GAUSSIAN $98 \operatorname{code}^{29}$ were used in our computations. The geometries were optimized without any symmetry constraint for different spin multiplicities. For each cluster the optimization was performed by starting from several initial structures to locate through exploration of the potential energy surface, the geometry corresponding to the 
global minimum. It should also be pointed out that the accuracy of the density functional theory in treating transitional metal systems does have limitations since they possess spin multiplet structures that are energetically close to each other. This problem has been extensively discussed in the literature $^{30}$ and we refer the reader to earlier papers. It is sufficient to mention that the DFT-GGA based calculations ${ }^{26}$ on $3 d$ transition metal cations interacting with a single benzene molecule have yielded geometry, bond lengths, and dissociation energies in good agreement with CCSD and CCSD(T) (coupled cluster method with singles and doubles and noniterative inclusion of triple excitations) calculation ${ }^{25}$ as well as experiment. ${ }^{13,32}$ In addition, the consistent agreement between present calculations and available experiments in $\mathrm{Ni}_{n}(\mathrm{Bz})_{m}$ systems gives us confidence in the predictions of the DFT-GGA level of theory.

\section{RESULTS AND DISCUSSIONS}

In order to assess the accuracy of the calculated geometries and energetics of the $\mathrm{Ni}$-benzene complexes we have used Ni-benzene with $C_{6 v}$ geometry as a test case. We have calculated the equilibrium bond lengths, binding energy (i.e., energy needed to dissociate $\mathrm{Ni}-\mathrm{Bz}$ to $\mathrm{Ni}$ and $\mathrm{Bz}$ ), and the adiabatic ionization potential using the frozen core LANL2DZ basis and the all-electron $6-311 \mathrm{G}^{* *}$ basis sets. The $\mathrm{C}-\mathrm{C}, \mathrm{C}-\mathrm{H}$, and $\mathrm{NiC}$ distances obtained using the LANL2DZ basis are, respectively, $1.44 \AA, 1.09 \AA$, and 2.14 $\AA$ and these agree very well with the corresponding values of $1.44 \AA, 1.09 \AA$, and $1.98 \AA$ obtained from the $6-311 \mathrm{G}^{* *}$ basis set. Similarly the binding energy and the ionization potential of $\mathrm{Ni}-\mathrm{Bz}$ using the $6-311 \mathrm{G}^{* *}$ basis are $1.54 \mathrm{eV}$ and $5.78 \mathrm{eV}$ while those using the LANL2DZ basis are $1.22 \mathrm{eV}$ and $6.17 \mathrm{eV}$. Note that while the bond lengths agree within approximately $0.2 \AA$, the energies agree within about $0.3 \mathrm{eV}$. Comparisons of these two basis sets in other systems ${ }^{31}$ have resulted in similar conclusions. In view of the computational cost, we have decided to use the LANL2DZ basis for all the remaining calculations. The above comparison should be viewed in terms of the limitations of the predicted results.

\section{A. Geometries}

In Fig. 1 we present the ground state geometries of neutral $\mathrm{Ni}_{n}(\mathrm{Bz})_{m}(n \leqslant 3, m \leqslant 2)$ complexes. The corresponding geometries for the ground state of cationic complexes are shown in Fig. 2. In agreement with previous calculations, ${ }^{25-27}$ the geometries of the neutral and cationic $\mathrm{NiBz}$ assume a $C_{6 v}$ symmetry. The geometry of $\mathrm{Ni}_{2} \mathrm{Bz}$ [Fig. 1(b)] consists of a $\mathrm{Ni}_{2}$ dimer with a bond length of $2.27 \AA$ bonded to four of the carbon atoms of a slightly distorted benzene ring. Note that in $\mathrm{Ni}_{3} \mathrm{Bz}$ [Fig. 1(c)], the distortions of the ring are reduced while the $\mathrm{Ni}_{3}$ trimer in a nearly equilateral triangular configuration binds to all the six carbon atoms of the benzene molecule. The ground state geometry of neutral $\mathrm{Ni}(\mathrm{Bz})_{2}$ in Fig. 1(d) is characterized by the second benzene molecule sliding on top of the $\mathrm{Ni}$ atom until its $\mathrm{C}-\mathrm{C}$ bond lies just above it. In addition, this molecule is tilted with respect to the bottom benzene plane and is accompanied by minor changes in the $\mathrm{C}-\mathrm{C}$ and $\mathrm{C}-\mathrm{H}$ bond as well as $\mathrm{C}-\mathrm{H}$

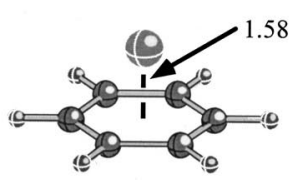

(a)

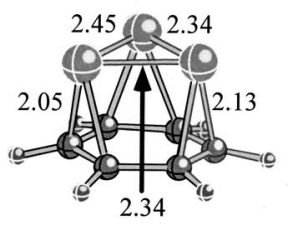

(c)

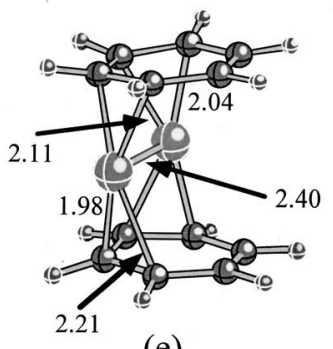

(e)

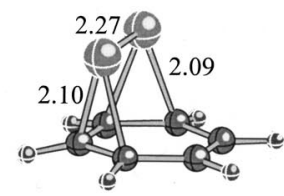

(b)

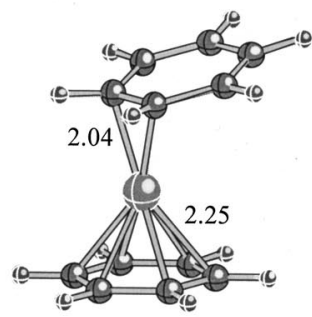

(d)

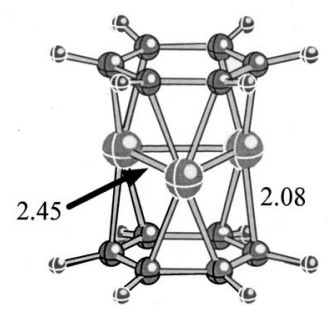

(f)
FIG. 1. Ground state geometries of neutral $\mathrm{Ni}_{n}(\mathrm{Bz})_{m}$ clusters obtained without symmetry constraint. Some of the representative bond distances $(\AA)$ are marked in the figure for clarity.

bond angle. In the cationic $\mathrm{Ni}(\mathrm{Bz})_{2}^{+}$complex $[$Fig. 2(d)] the structure approaches a more symmetric form with the two benzene planes becoming more parallel and on top of each other than in the corresponding neutral complex in Fig. 1(d). The structure of neutral $\mathrm{Ni}_{2}(\mathrm{Bz})_{2}$ [Fig. 1(e)] is composed of a $\mathrm{Ni}_{2}$ dimer with a bond length of $2.40 \AA$ with its axis nearly parallel to the two benzene planes on either side. We recall that the calculated bond length ${ }^{32}$ of a pure Ni dimer is 2.13 $\AA$. The two $\mathrm{Ni}$ atoms in $\mathrm{Ni}_{2}(\mathrm{Bz})_{2}$ lie along the middle of the $\mathrm{C}-\mathrm{C}$ bond. Its cationic complex $\mathrm{Ni}_{2}(\mathrm{Bz})_{2}^{+}$[Fig. 2(e)] has a similar topology as the neutral complex, but the $\mathrm{C}-\mathrm{C}$ and $\mathrm{C}-\mathrm{H}$ bonds and angles are distorted. This distortion nearly disappears in $\mathrm{Ni}_{3}(\mathrm{Bz})_{2}$ complex in both neutral and cationic configurations [Fig. 1(f), Fig. 2(f)]. The $\mathrm{Ni}_{3}$ cluster intercalated between the two benzene molecules forms an almost equilateral triangle with a $\mathrm{Ni}-\mathrm{Ni}$ bond length of $2.45 \AA$ in neutral complex. In the cationic complex, the structure is an isosceles triangle with bond lengths of 2.39 and $2.46 \AA$. Note that the calculated structure ${ }^{32}$ of pure $\mathrm{Ni}_{3}$ cluster is a nearly equilateral triangle with a Ni-Ni bond of $2.20 \AA$. Thus, the structure of $\mathrm{Ni}_{3}$ caged between two benzene molecules, remains essentially in the same form as in bare $\mathrm{Ni}_{3}$ although with a slightly stretched bond. Note that similar behavior was found for $\mathrm{Ni}_{2}$.

The spin multiplicities of all the clusters studied here, with the exception of neutral $\mathrm{Ni}_{2}(\mathrm{Bz}), \mathrm{Ni}_{3}(\mathrm{Bz})$, and $\mathrm{Ni}_{3}(\mathrm{Bz})^{+}$ are reduced to their lowest possible value namely singlet if the number of electrons is even, and doublet if the number of 


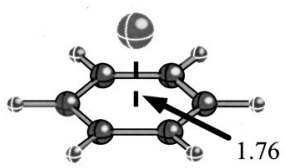

(a)

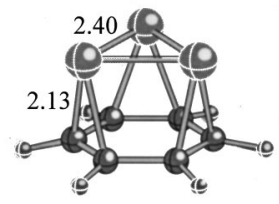

(c)

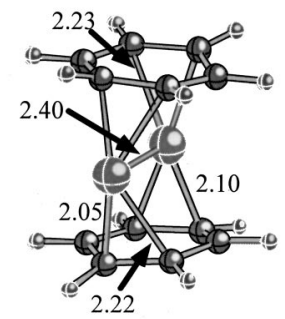

(e)

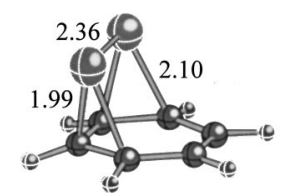

(b)

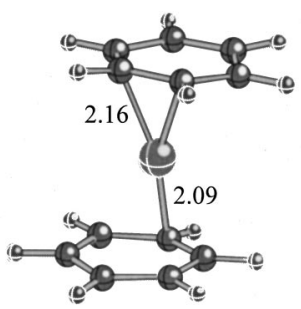

(d)

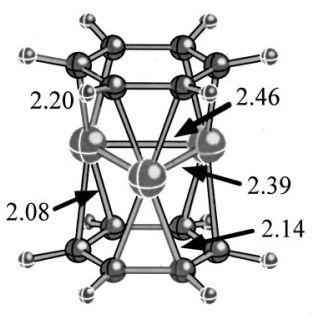

(f)

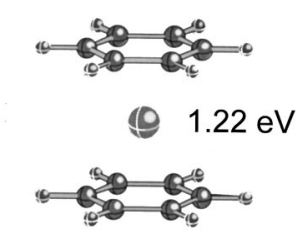

(a)

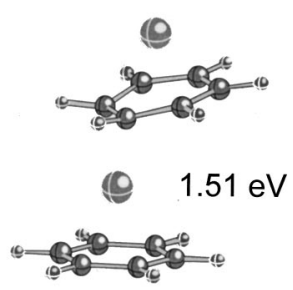

(c)

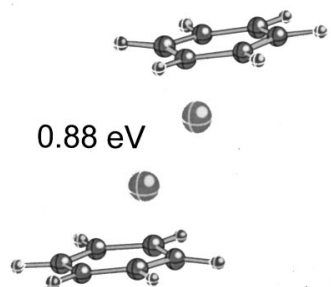

(b)

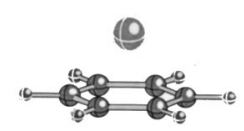

$1.57 \mathrm{eV} \theta$

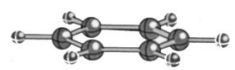

(d)
FIG. 2. Ground state geometries of cationic $\mathrm{Ni}_{n}(\mathrm{Bz})_{m}^{+}$clusters obtained without symmetry constraint. Some of the bond distances $(\AA)$ are marked in the figures for clarity.

electrons is odd. The ground state configuration of both $\mathrm{Ni}_{2}(\mathrm{Bz})$ and $\mathrm{Ni}_{3}(\mathrm{Bz})$ neutrals in the spin triplet state are, respectively, $0.19 \mathrm{eV}$ and $0.42 \mathrm{eV}$ lower in energy than the corresponding singlet states. In Fig. 3 we compare the geometries of the spin triplet configurations with those of the singlet states. Note that apart from a slightly more symmetric

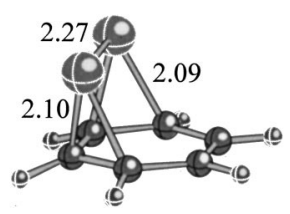

(a)

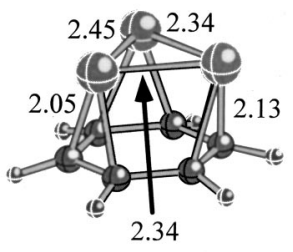

(c)

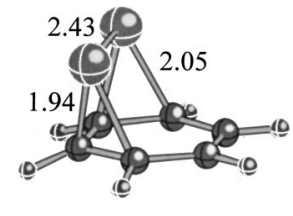

(b)

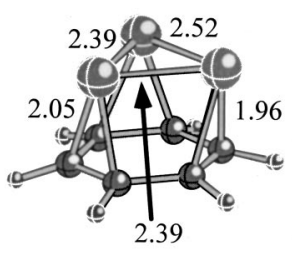

(d)
FIG. 3. Comparison of the ground states [(a) and (c)] and the lowest lying excited states $[(\mathrm{b})$ and $(\mathrm{d})]$ of neutral $\mathrm{Ni}_{2}(\mathrm{Bz})$ and $\mathrm{Ni}_{3}(\mathrm{Bz})$ complexes. The ground and the excited states are in spin triplet and spin singlet configurations, respectively.

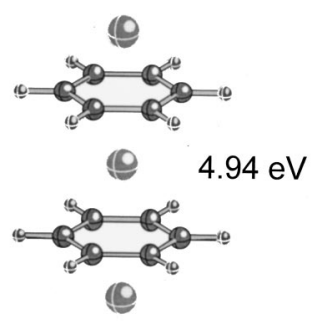

(e)

FIG. 4. Geometries of some of the higher energy isomers of neutral $\mathrm{Ni}_{n}(\mathrm{Bz})_{m}$ complexes. For each of these isomers we present their energies, $\Delta E$ measured with respect to their corresponding ground state in Fig. 1.

structure of the triplet states, the geometries including the bond lengths are very similar. We will return to this aspect later in the paper.

We have also studied the equilibrium geometries of some higher energy isomers of $\mathrm{Ni}_{n}(\mathrm{Bz})_{m}$ complexes. These structures for neutral and cationic complexes are given in Figs. 4 and 5, respectively. The energy difference between these structures and corresponding ground state geometries in Figs. 1 and 2 are listed in Figs. 4 and 5, respectively, The energies of $\mathrm{Ni}(\mathrm{Bz})_{2}$ and $\mathrm{Ni}(\mathrm{Bz})_{2}^{+}$complexes optimized with (a)
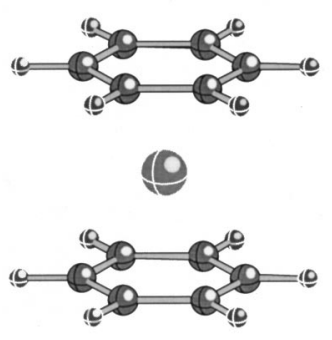

$0.25 \mathrm{eV}$ (b)

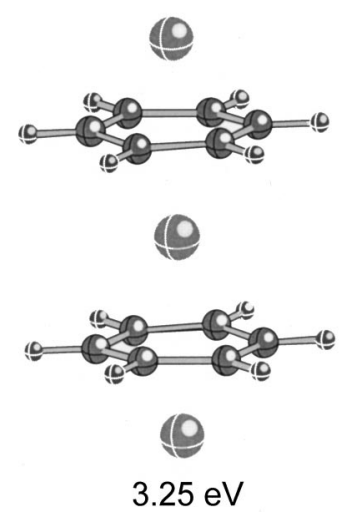

FIG. 5. Geometries of some of the higher energy isomers of cationic $\mathrm{Ni}_{n}(\mathrm{Bz})_{m}^{+}$complexes. For each of these isomers we present their energies, $\Delta E$ measured with respect to their corresponding ground state in Fig. 2. 


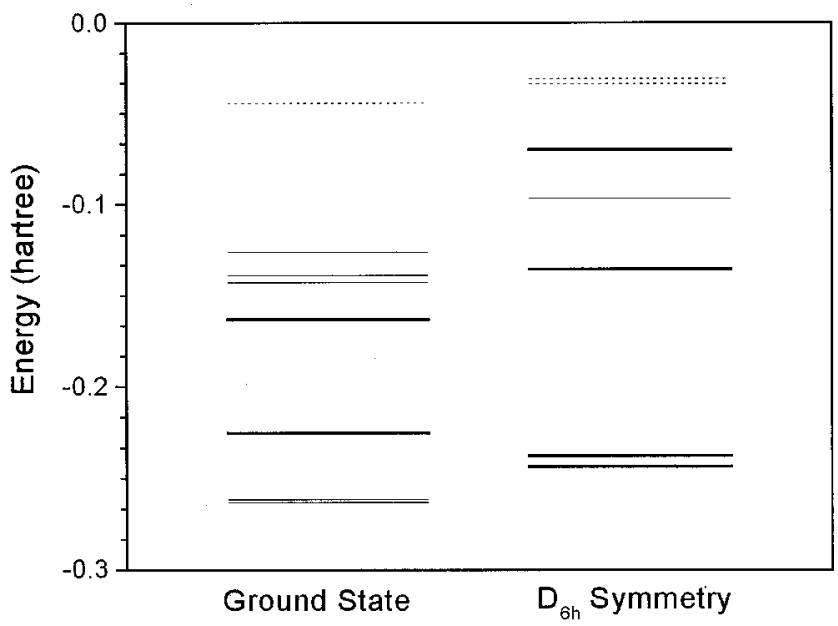

FIG. 6. Molecular energy levels for the ground state [Fig. 1(d)] and the $D_{6 h}$ [Fig. 4(a)] structures of neutral $\mathrm{Ni}(\mathrm{Bz})_{2}$. The unoccupied states are represented by dashed lines. The degenerate levels are shown as thick lines.

$D_{6 h}$ symmetry constraint lie $1.22 \mathrm{eV}$ and $0.25 \mathrm{eV}$, respectively, above the ground state structure of Figs. 1(d) and 2(d). Note that the small energy difference between the ground state and higher energy isomer of $\mathrm{Ni}(\mathrm{Bz})_{2}^{+}$compared to its neutral counterpart is due to the nearly symmetrical configuration of the cationic ground state.

The origin of the significant energy lowering of the neutral $\mathrm{Ni}(\mathrm{Bz})_{2}$ complex resulting from its structural deviation from the $D_{6 h}$ symmetry can be understood by plotting its molecular orbital (MO) energy levels (see Fig. 6) corresponding to the structures in Figs. 1(d) and 4(a). In the $D_{6 h}$ configuration [Fig. 4(a)], the highest occupied molecular orbital (HOMO) is doubly degenerate and is fully occupied. Consequently, it is not Jahn-Teller active. The HOMO-1 orbital is nondegenerate while the other lower lying orbitals are, once again, doubly degenerate. As the structure distorts, the degeneracies of the orbitals are lifted. But more importantly, the energy levels shift to lower values due to a stronger bonding of the Ni atom with two of the nearest neighbor carbon atoms of one of the benzene rings. The shifting of MO levels of the ground state structure in comparison to that of the $D_{6 h}$ symmetry is also partly due to the difference in the Mulliken charges on the $\mathrm{Ni}$ atom. It is more negative $(-0.141)$ in the $D_{6 h}$ structure than it is $(-0.039)$ in the ground state structure. It is well known that the energy levels of a negatively charged atom are always pushed to a higher energy than those of the neutral atom. Thus the lowering of the total energy of neutral $\mathrm{Ni}(\mathrm{Bz})_{2}$ cluster in the distorted structure is due to chemical interaction and not due to JahnTeller effect. We should caution the reader that in the density functional theory the one-electron orbital energies do not have much meaning. The above discussion must, therefore, be viewed as providing a qualitative understanding of why the distortion in the geometry leads to the lowering of energy.

For $\mathrm{Ni}_{2}(\mathrm{Bz})_{2}$ complexes we have studied three other structures, two of which [Figs. 4(b) and 4(c)] were optimized without any symmetry constraint while the third one [Fig. 4(d)] was restricted to $C_{6 v}$ symmetry. Note that all these structures are higher in energy compared to the ground state in Fig. 1(e) and lie, respectively, $0.88 \mathrm{eV}, 1.51 \mathrm{eV}$, and 1.57 $\mathrm{eV}$ above it. Similarly, the $D_{6 h}$ structure of $\mathrm{Ni}_{3}(\mathrm{Bz})_{2}$ in Fig. 4(e) lies $4.94 \mathrm{eV}$ above the ground state caged structure in Fig. 1(f). The optimized $D_{6 h}$ structure of $\mathrm{Ni}_{3}(\mathrm{Bz})_{2}^{+}$given in Fig. 5(b) is $3.25 \mathrm{eV}$ higher in energy than its corresponding ground state structure in Fig. 2(f).

The topology of the $\mathrm{Ni}_{n}(\mathrm{Bz})_{m}$ clusters can be used to shed some qualitative understanding of their reactive properties. Although the reactivity of $\mathrm{Co}_{n}(\mathrm{Bz})_{m}$ to $\mathrm{NH}_{3}$ has been studied at some length, similar experiments involving $\mathrm{Ni}_{n}(\mathrm{Bz})_{m}$ are lacking. Since the mass ion distributions of $\mathrm{Co}_{n}(\mathrm{Bz})_{m}$ and $\mathrm{Ni}_{n}(\mathrm{Bz})_{m}$ exhibit some similar features, one could argue that their chemistry is also similar to each other. Thus, in analogy with $\mathrm{Co}_{n}(\mathrm{Bz})_{m}$, we expect $\mathrm{Ni}_{2}(\mathrm{Bz})_{2}$ and $\mathrm{Ni}_{3}(\mathrm{Bz})_{2}$ to react with $\mathrm{NH}_{3}$ while $\mathrm{Ni}_{2}(\mathrm{Bz})_{3}$ and $\mathrm{Ni}_{3}(\mathrm{Bz})_{3}$ may be unreactive. The optimized structures in Figs. 1 and 2 reveal that if these clusters are exposed to $\mathrm{NH}_{3}$, the metal atoms lying at the edge in the intercalating layer can be accessible for chemical bonding. Thus, these clusters will be depleted from the mass spectra if exposed to reagent molecules. This is consistent with the experimental finding in the $\mathrm{Co}_{n}(\mathrm{Bz})_{m}$ system where clusters corresponding to $(n, m)$ $=(1,2),(2.2)$, and $(3,2)$ are reactive towards $\mathrm{NH}_{3}$. To achieve a quantitative understanding of this reactivity, theoretical studies of the optimized structures of these complexes interacting with $\mathrm{NH}_{3}$ will certainly be needed. We are currently studying these systems.

\section{B. Vertical and adiabatic ionization potential}

We now discuss the vertical and adiabatic ionization potentials as well as the binding energies of neutral $\mathrm{Ni}_{n}(\mathrm{Bz})_{m}$ complexes. The ionization potential (IP) is defined as the energy needed to remove an electron from the neutral cluster, namely,

$$
\mathrm{IP}=E\left(\mathrm{Ni}_{n}\left(\mathrm{Bz}_{m}\right)^{+}-E\left(\mathrm{Ni}_{n} \mathrm{Bz}_{m}\right) .\right.
$$

Here, $E$ is the total energy of the cluster and does not include zero point contribution. If the geometry of the ionized cluster is assumed to be that of its neutral, the corresponding ionization potential is termed vertical ionization potential (VIP). On the other hand, if the ionized cluster is allowed to relax, the resulting energy difference between the neutral and the relaxed cation is termed as the adiabatic ionization potential (AIP). The difference between VIP and AIP then provides a signature of the energy gain resulting from the structural relaxation of the cationic cluster. In Table I we list these ionization potentials and compare them with available experiments. The calculated vertical ionization potential of $\mathrm{NiBz}$ is $6.36 \mathrm{eV}$ which agrees well with the experimental value that lies in the range of $5.99 \mathrm{eV}-6.42 \mathrm{eV}$. Similarly, the calculated VIP of $\mathrm{Ni}(\mathrm{Bz})_{2}$ of $6.12 \mathrm{eV}$ agrees well with the experimental value of $5.86 \mathrm{eV}$. If, instead, calculations were carried out with the $D_{6 h}$ structure in Fig. 4(a), the computed vertical ionization potential of $\mathrm{Ni}(\mathrm{Bz})_{2}$ will be $4.7 \mathrm{eV}$-in disagreement with experiment. This confirms the accuracy of the ground state structure in Fig. 1(d). The energy differences between VIP and AIP in all clusters studied are less than 0.4 
TABLE I. Metal atomization energies [see Eq. (2)], vertical and adiabatic ionization potentials of $\mathrm{Ni}_{n}(\mathrm{Bz})_{m}$ clusters.

\begin{tabular}{|c|c|c|c|c|}
\hline \multirow[b]{2}{*}{ Cluster } & \multicolumn{2}{|c|}{ VIP (eV) } & \multirow[b]{2}{*}{ AIP (ev) } & \multirow{2}{*}{$\begin{array}{c}\text { Metal atomization } \\
\text { energy }(\mathrm{eV})\end{array}$} \\
\hline & Theory & Expt. & & \\
\hline $\mathrm{Ni}$ & 7.77 & 7.64 & & \\
\hline $\mathrm{Bz}$ & 9.20 & 9.24 & & \\
\hline $\mathrm{NiBz}$ & 6.36 & $5.99-6.42$ & 6.17 & 1.22 \\
\hline $\mathrm{Ni}_{2} \mathrm{Bz}$ & 5.81 & & 5.70 & 3.09 \\
\hline $\mathrm{Ni}_{3} \mathrm{Bz}$ & 5.70 & & 5.62 & 5.48 \\
\hline $\mathrm{Ni}(\mathrm{Bz})_{2}$ & 6.12 & 5.86 & 5.68 & 2.56 \\
\hline $\mathrm{Ni}_{2}(\mathrm{Bz})_{2}$ & 6.37 & & 5.76 & 5.25 \\
\hline $\mathrm{Ni}_{3}(\mathrm{Bz})_{2}$ & 6.34 & & 6.12 & 8.58 \\
\hline
\end{tabular}

$\mathrm{eV}$. This is because the relaxation of the geometry following ionization of all clusters is rather small. The vertical ionization potentials of all $\mathrm{Ni}_{n}(\mathrm{Bz})_{m}$ complexes studied here lie in the range of 5.5-6.4 eV. For $\mathrm{Ni}_{n} \mathrm{Bz}$ complexes the VIP decreases sharply from $n=1$ to $n=2$, while in $\mathrm{Ni}_{n}(\mathrm{Bz})_{2}$ complexes it increases slightly over the same range. No experimental values are available for comparison.

\section{Metal atomization and dissociation energies}

Also listed in Table I are the metal atomization energies of neutral $\mathrm{Ni}_{n}(\mathrm{Bz})_{m}$ complexes. We define this as the energy needed to fragment the cluster into individual nickel atoms and benzene molecules, namely,

$$
E_{b}(n, m)=-\left\{E\left[\mathrm{Ni}_{n}(\mathrm{Bz})_{m}\right]-n E(\mathrm{Ni})-m E(\mathrm{Bz})\right\} .
$$

The metal atomization energy of $\mathrm{NiBz}$ is $1.22 \mathrm{eV}$. As $\mathrm{Ni}$ atoms are successively added, keeping the same benzene content, the metal atomization energy of $\mathrm{Ni}_{n} \mathrm{Bz}$ increases by $1.93 \mathrm{eV}$ for $n=1$ to 2 and by $2.39 \mathrm{eV}$ for $n=2-3$. Similarly, in $\mathrm{Ni}_{2}(\mathrm{Bz})_{2}$ complexes, the metal atomization energy increases by $2.69 \mathrm{eV}$ for $n=1$ to 2 and $3.33 \mathrm{eV}$ for $n=2-3$. This systematic increase in binding either by increasing $\mathrm{Ni}$ content or benzene content, or both, results not only because of the interaction between metal atoms but also because of interaction between metal atoms and benzene. We should point out that the calculated atomization energies ${ }^{32}$ of $\mathrm{Ni}_{2}$ and $\mathrm{Ni}_{3}$ are $2.62 \mathrm{eV}$ and $5.11 \mathrm{eV}$, respectively. Note that these energies are significantly smaller than $\mathrm{Ni}_{n}(\mathrm{Bz})_{m}$ complexes having the same Ni content. The strength of bonding can also be analyzed by calculating the energy needed to dissociate a $\mathrm{Ni}_{n}(\mathrm{Bz})$ cluster into a $\mathrm{Ni}_{n}$ cluster and a benzene molecule. The dissociation energy of $\mathrm{Ni}_{2} \mathrm{Bz}$ with respect to $\mathrm{Ni}_{2}$ and $\mathrm{Bz}$ is $0.47 \mathrm{eV}$ while that of $\mathrm{Ni}_{3} \mathrm{Bz}$ with respect to $\mathrm{Ni}_{3}$ and $\mathrm{Bz}$ is $0.37 \mathrm{eV}$. The corresponding energies with 2 benzene molecules is much larger.

We now discuss the dissociation energies of neutral and cationic $\mathrm{Ni}_{n}(\mathrm{Bz})_{m}$ clusters. These have been studied experimentally for the cation using collision induced dissociation ${ }^{13}$ as well as mobility experiments. ${ }^{33}$ The dissociation of these complexes can occur along different pathways where the fragment could be a benzene molecule, a metal atom or their clusters, or a smaller NiBz complex. If the parent complex is
TABLE II. Dissociation energies, $D_{e}$ of neutral $\mathrm{Ni}_{n}(\mathrm{Bz})_{m}$ along different channels.

\begin{tabular}{lccc}
\hline \hline & & \multicolumn{2}{c}{$D_{e}(\mathrm{eV})$} \\
\cline { 3 - 4 } Parent cluster & Channel & Theory & Expt. \\
\hline $\mathrm{NiBz}$ & $\mathrm{Ni}+\mathrm{Bz}$ & 1.22 & $0.87-1.30$ \\
& & & \\
$\mathrm{Ni}(\mathrm{Bz})_{2}$ & $\mathrm{NiBz}+\mathrm{Bz}$ & 1.40 & \\
& & & \\
$\mathrm{Ni}_{2}(\mathrm{Bz})_{2}$ & $\mathrm{Ni}{ }_{2} \mathrm{Bz}+\mathrm{Bz}$ & 1.97 & \\
& $\mathrm{Ni}(\mathrm{Bz})_{2}+\mathrm{Ni}$ & 2.69 & \\
& $\mathrm{NiBz}+\mathrm{NiBz}$ & 2.92 & \\
& & & \\
$\mathrm{Ni}_{3}(\mathrm{Bz})_{2}$ & $\mathrm{Ni}_{3} \mathrm{Bz}+\mathrm{Bz}$ & 2.67 & \\
& $\mathrm{Ni}_{2} \mathrm{Bz}+\mathrm{NiBz}$ & 3.14 & \\
& $\mathrm{Ni}_{2}(\mathrm{Bz})_{2}+\mathrm{Ni}$ & 4.32 & \\
\hline \hline
\end{tabular}

charged, one has to study which fragment carries the change. In the dissociation of $\mathrm{Ni}_{n}(\mathrm{Bz})_{m}^{+}$complexes, the channels that have been studied experimentally involve

$$
\mathrm{Ni}_{n}(\mathrm{Bz})_{m} \rightarrow \mathrm{Ni}_{n}(\mathrm{Bz})_{m-1}^{+}+\mathrm{Bz} .
$$

In this work we have evaluated the energetics of several possible dissociation channels including the one in Eq. (3) and compared the energies with experiment wherever possible.

The dissociation energies of $\mathrm{NiBz}$ and $\mathrm{NiBz}^{+}$(see Tables II and III) are, respectively, $1.22 \mathrm{eV}$ and $2.57 \mathrm{eV}$ and compare very well with corresponding experimental values of $0.87-1.30 \mathrm{eV}$ and $2.52 \mathrm{eV}$, respectively. Note that the agreement achieved here is better than those reported earlier ${ }^{26,27}$ which is primarily due to the improved energies of the atoms in the GAUSSIAN 98 code. The dissociation energies of $\mathrm{Ni}(\mathrm{Bz})_{2} \rightarrow \mathrm{NiBz}+\mathrm{Bz}$ and $\mathrm{Ni}(\mathrm{Bz})_{2}^{+} \rightarrow \mathrm{NiBz}^{+}+\mathrm{Bz}$ are, respectively, $1.40 \mathrm{eV}$ and $1.91 \mathrm{eV}$. There is no experimental value of the dissociation energy of the neutral $\mathrm{Ni}(\mathrm{Bz})_{2}$ complex, but that for the cationic complex, $\mathrm{Ni}^{+}(\mathrm{Bz})_{2}$ agrees well with the experimental value of $1.70 \mathrm{eV}$ by Bowers and

TABLE III. Dissociation energies, $D_{e}$ of $\mathrm{Ni}_{n}(\mathrm{Bz})_{m}^{+}$cationic complexes along different channels.

\begin{tabular}{lccc}
\hline \hline & & \multicolumn{2}{c}{$D_{e}(\mathrm{eV})$} \\
\cline { 3 - 4 } Parent cluster & Channels & Theory & Expt. (Ref. 10) \\
\hline $\mathrm{NiBz}^{+}$ & $\mathrm{Ni}^{+}+\mathrm{Bz}$ & 2.57 & $2.52(0.11)$ \\
$\mathrm{Ni}(\mathrm{Bz})_{2}^{+}$ & $\mathrm{NiBz}^{+}+\mathrm{Bz}$ & 1.91 & $1.52(0.12)$ \\
& & & $1.70^{\mathrm{a}}$ \\
& & & \\
$\mathrm{Ni}_{2}(\mathrm{Bz})_{2}^{+}$ & $\mathrm{Ni}(\mathrm{Bz})^{+}+\mathrm{NiBz}$ & 1.90 & $>2.17^{\mathrm{a}}$ \\
& $\mathrm{Ni}_{2}(\mathrm{Bz})^{+}+\mathrm{Bz}$ & 2.60 & \\
& $\mathrm{Ni}(\mathrm{Bz})_{2}^{+}+\mathrm{Ni}$ & 3.35 & $>2.17^{\mathrm{a}}$ \\
$\mathrm{Ni}_{3}(\mathrm{Bz})_{2}^{+}$ & & & \\
& $\mathrm{Ni}_{3} \mathrm{Bz}^{+}+\mathrm{Bz}$ & 2.18 & \\
& $\mathrm{Ni}_{2} \mathrm{Bz}_{2}^{+}+\mathrm{Ni}$ & 2.97 & \\
& $\mathrm{Ni}_{2} \mathrm{Bz}^{+}+\mathrm{NiBz}$ & 3.72 & \\
& $\mathrm{Ni}_{2} \mathrm{Bz}^{+} \mathrm{NiBz}^{+}$ & 4.20 & \\
\hline \hline
\end{tabular}

${ }^{\mathrm{a} R e f e r e n c e} 11$. 
TABLE IV. Spin multiplicities $(M=2 S+1)$ of $\mathrm{Ni}_{n}(\mathrm{Bz})_{m}$ clusters and their cations.

\begin{tabular}{lccc}
\hline \hline Clusters & Spin multiplicity & Clusters & Spin multiplicity \\
\hline $\mathrm{Ni}$ & 3 & $\mathrm{Ni}^{+}$ & 2 \\
$\mathrm{Bz}$ & 1 & $\mathrm{Bz}^{+}$ & 2 \\
$\mathrm{NiBz}$ & 1 & $\mathrm{NiBz}^{+}$ & 2 \\
$\mathrm{Ni}{ }_{2} \mathrm{Bz}$ & 3 & $\mathrm{Ni}_{2} \mathrm{Bz}^{+}$ & 2 \\
$\mathrm{Ni}_{3} \mathrm{Bz}$ & 3 & $\mathrm{Ni}_{3} \mathrm{Bz}^{+}$ & 4 \\
$\left.\mathrm{Ni}^{+} \mathrm{Bz}\right)_{2}$ & 1 & $\mathrm{Ni}_{2}(\mathrm{Bz})_{2}^{+}$ & 2 \\
$\mathrm{Ni}_{2}(\mathrm{Bz})_{2}$ & 1 & $\mathrm{Ni}_{2}(\mathrm{Bz})_{2}^{+}$ & 2 \\
$\mathrm{Ni}_{3}(\mathrm{Bz})_{2}$ & 1 & $\mathrm{Ni}_{3}(\mathrm{Bz})_{2}+$ & 2 \\
\hline \hline
\end{tabular}

co-workers. ${ }^{33}$ An earlier experimental value obtained from collision induced dissociation ${ }^{13}$ yields $1.52(0.12) \mathrm{eV}$ for this channel.

The dissociation of $\mathrm{Ni}_{2}(\mathrm{Bz})_{2}$ and $\mathrm{Ni}_{3}(\mathrm{Bz})_{2}$ and their cations involve different possible channels. To calculate the energies needed for this dissociation along different channels, we need the total energies of neutral $\mathrm{Ni}(\mathrm{Bz})_{2}, \mathrm{Ni}_{2} \mathrm{Bz}, \mathrm{Ni}_{3} \mathrm{Bz}$, and their cations. The optimized geometries of these clusters and their corresponding total energies were calculated using the same procedure as outlined previously. The results are given in Figs. 1 and 2. The corresponding total energies were used to obtain the dissociation energies given in Tables II and III. Note that the path requiring the least energy for fragmentation of $\mathrm{Ni}_{2}(\mathrm{Bz})_{2}$ involves dissociation into $\mathrm{Ni}_{2} \mathrm{Bz}+\mathrm{Bz}$ and that of $\mathrm{Ni}_{3}(\mathrm{Bz})_{2}$ into $\mathrm{Ni}_{3} \mathrm{Bz}+\mathrm{Bz}$. There are no experimental values available for comparison of these results in Table II. The dissociation of $\mathrm{Ni}_{2}(\mathrm{Bz})_{2}^{+}$into $\mathrm{NiBz}^{+}+\mathrm{NiBz}$ requires the least energy among all possible channels. No experimental value is available for this channel, but the experimental lower limit of $2.17 \mathrm{eV}$ (Ref. 32) for its dissociation into $\mathrm{Ni}_{2}(\mathrm{Bz})^{+}+\mathrm{Bz}$ is consistent with our calculated energy of $2.60 \mathrm{eV}$. Similarly, the energy needed to dissociate $\mathrm{Ni}_{3}(\mathrm{Bz})_{2}^{+}$to $\mathrm{Ni}_{3} \mathrm{Bz}^{+}+\mathrm{Bz}$ is also consistent with the experimental lower limit ${ }^{33}$ of $2.17 \mathrm{eV}$. It will be useful to have additional experimental values to compare with our predicted results in Tables II and III.

We now turn to what we consider to be one of the most interesting properties of $\mathrm{Ni}_{n}(\mathrm{Bz})_{m}$ complexes, namely their magnetic properties. In Table IV we summarize the spin multiplicities of these complexes. The ground states of all neutral $\mathrm{Ni}_{n}(\mathrm{Bz})_{m}$ clusters studied here, with the exception of $\mathrm{Ni}_{2} \mathrm{Bz}$ and $\mathrm{Ni}_{3} \mathrm{Bz}$, are singlets and the net magnetic moment at the $\mathrm{Ni}$ site is zero. On the other hand, the magnetic moment/ atom of pure $\mathrm{Ni}, \mathrm{Ni}_{2}$, and $\mathrm{Ni}_{3}$ species are, respectively, 2.0 $\mu_{B}, 1.0 \mu_{B}$, and $0.67 \mu_{B}$. In charged $\mathrm{Ni}_{n}\left(\mathrm{Bz}_{m}^{+}\right.$clusters, all except the $\mathrm{Ni}_{3} \mathrm{Bi}^{+}$have the lowest spin multiplicity, namely doublet. The quenching of the $\mathrm{Ni}_{n}$ moment in $\mathrm{Ni}_{n}(\mathrm{Bz})_{m}$ arises due to the strong hybridization between the $3 d$ electrons of nickel and the $\pi$-electrons of benzene. Experimental confirmation of this prediction is awaited. We should point out that the quenching of the magnetic moment of $\mathrm{Ni}$ as a consequence of hybridization has been predicted in several $\mathrm{Ni}-\mathrm{C}$ structures. ${ }^{34}$

\section{CONCLUSIONS}

In summary, we have obtained geometries and total energies of neutral and cationic $\mathrm{Ni}_{n}(\mathrm{Bz})_{m} \quad(n \leqslant 3, m \leqslant 2)$ clusters corresponding to both ground and higher energy isomeric states. The ground state geometries confirm the earlier experimental speculation that benzene molecules tend to cage the $\mathrm{Ni}$ clusters. The good agreement we have achieved between the experimental and theoretical ionization potentials and dissociation energies give support to the ground state geometries obtained in this work. We also found that the neutral $\mathrm{Ni}$ cluster atoms caged by benzene molecules with the exception of $\mathrm{Ni}_{2} \mathrm{Bz}$ and $\mathrm{Ni}_{3} \mathrm{Bz}$ completely lose their magnetism. It will be interesting to see if this trend persists in larger $\mathrm{Ni}_{n}(\mathrm{Bz})_{m}$ complexes, and if this unexpected behavior is confined only to Ni-based organometallic systems.

\section{ACKNOWLEDGMENTS}

This work was supported, in part, by a grant (DEFG0296ER45579) from the Department of Energy. The authors are thankful to Professor M. Bowers for having shared his experimental results prior to publication and for useful discussions.

${ }^{1}$ Comprehensive Organometallic Chemistry, edited by G. Wilkinson, F. G. A. Stone, and E. W. Abel (Pergamon, New York, 1982); P. Braga, P. J. Dyson, F. Grepioni, and F. G. Johnson, Chem. Rev. 94, 1585 (1994).

${ }^{2}$ R. Sessoli, H. Tsai, A. R. Schake, S. Wang, J. B. Vincent, K. Folting, D. Gatteschi, G. Christou, and D. N. Hendrickson, J. Am. Chem. Soc. 115, 1804 (1993).

${ }^{3}$ J. C. Ma and D. A. Dougherty, Chem. Rev. 97, 1303 (1997).

${ }^{4}$ D. A. Dougherty, Science 271, 163 (1996).

${ }^{5}$ J. W. Caldwell and P. A. Kollman, J. Am. Chem. Soc. 117, 4177 (1995).

${ }^{6}$ D. B. Jacobson and B. S. Freiser, J. Am. Chem. Soc. 106, 3900 (1984).

${ }^{7}$ D. B. Jacobson and B. S. Freiser, J. Am. Chem. Soc. 106, 4623 (1984).

${ }^{8}$ D. Rufus, A. Ranatunga, and B. S. Freiser, Chem. Phys. Lett. 233, 319 (1995).

${ }^{9}$ S. Afzaal and B. S. Freiser, Chem. Phys. Lett. 218, 254 (1994).

${ }^{10}$ K. F. Willey, P. Y. Cheng, M. B. Bishop, and M. A. Duncan, J. Am. Chem. Soc. 113, 4721 (1991)

${ }^{11}$ K. F. Willey, C. S. Yeh, D. L. Robbins, and M. A. Duncan, J. Phys. Chem. 96, 9106 (1992)

${ }^{12}$ Y. M. Chen and P. B. Armentrout, Chem. Phys. Lett. 210, 123 (1993).

${ }^{13}$ F. Meyer, F. A. Khan, and P. B. Armentrout, J. Am. Chem. Soc. 117, 9740 (1995).

${ }^{14}$ R. C. Dunbar, S. J. Klippenstein, J. Hrusak, D. Stöckigt, and H. Schwartz, J. Am. Chem. Soc. 118, 5277 (1996).

${ }^{15}$ Y. P. Ho, Y. Yang, S. J. Klippenstein, and R. C. Dunbar, J. Phys. Chem. 101, 3338 (1997).

${ }^{16}$ K. Hoshino, T. Kurikawa, H. Takeda, A. Nakajima, and K. Kaya, J. Phys. Chem. 99, 3053 (1995).

${ }^{17}$ K. Judai, M. Hirano, H. Kawamata, S. Yabushita, A. Nakajima, and K. Kaya, Chem. Phys. Lett. 270, 23 (1997).

${ }^{18}$ J. E. Reddic, J. C. Robinson, and M. A. Duncan, Chem. Phys. Lett. 279, 203 (1997).

${ }^{19}$ A. Nakajima, S. Nagano, H. Takeda, T. Kurikawa, and K. Kaya, J. Chem. Phys. 107, 6491 (1997).

${ }^{20}$ P. Weis, P. R. Kemper, and M. T. Bowers, J. Phys. Chem. A 101, 8207 (1997).

${ }^{21}$ C. Y. Lin, Q. Chen, H. Chen, and B. S. Freiser, J. Phys. Chem. A 101, 6023 (1997)

${ }^{22}$ T. Kurikawa, H. Takeda, M. Hirano, K. Judai, T. Arita, S. Nagao, A. Nakajima, and K. Kaya, Organometallics 18, 1430 (1999).

${ }^{23}$ S. M. Mattar and W. Hamilton, J. Phys. Chem. 93, 2997 (1989).

${ }^{24}$ C. W. Bauschlicher, H. Partridge, and S. R. Langhoff, J. Phys. Chem. 96, 3273 (1992) 
${ }^{25}$ C. W. Bauschlicher, H. Partridge, and S. R. Langhoff, J. Phys. Chem. 96, 3273 (1992).

${ }^{26}$ R. Pandey, B. K. Rao, P. Jena, and J. M. Newsam, Chem. Phys. Lett. 321, 142 (2000).

${ }^{27}$ R. Pandey, B. K. Rao, P. Jena, and M. A. Blanco, J. Am. Chem. Soc. 123, 3799 (2001).

${ }^{28}$ T. Yasuike and S. Yabushita, J. Phys. Chem. A 103, 4533 (1999).

${ }^{29}$ M. J. Frisch, G. W. Trucks, H. B. Schlegel et al., GAUSSIAN 98, Revision A.7, Gaussian, Inc., Pittsburgh, PA, 1998; also see references therein.
${ }^{30}$ G. L. Gutsev, B. K. Rao, and P. Jena, J. Phys. Chem. A 104, 5374 (2000), and references therein.

${ }^{31}$ B. K. Rao and P. Jena, J. Chem. Phys. 115, 778 (2001).

${ }^{32}$ S. E. Weber and P. Jena, Chem. Phys. Lett. 281, 401 (1997), and references therein.

${ }^{33} \mathrm{M}$. T. Bowers (private communication)

${ }^{34}$ D. M. Duffy and J. A. Blackman, Phys. Rev. B 58, 7443 (1998); D. Changgeng, Y. Jinlong, C. Xiangyuan, and C. T. Chan, J. Chem. Phys. 111, 8481 (1999). 